\title{
Duodenogastric reflux after gastric surgery and in gastric ulcer disease: continuous measurement with a sodium ion selective electrode
}

\author{
Anne Smythe, Daniel O’Leary, Alan G Johnson
}

\begin{abstract}
Duodenogastric reflux (DGR) was investigated with a sodium ion selective electrode in 10 normal controls, 10 patients with persistent pain after gastric surgery, and five patients with gastric ulcer. During an average study time of two and a half hours, normal controls had reflux for $12 \%$ of the study, whereas patients after gastric surgery had reflux for $91 \%$ of the study time $(p<0.0002)$. Patients with a gastric ulcer had reflux on average for $67 \%$ of the study $(p<0.001)$. The patients who had had gastric surgery had several symptoms, but there was no association between the number or nature of symptoms and the severity of DGR as determined by the sodium electrode. Patients with positive bile provocation tests did not show any significant difference in the duration of reflux compared with those with a negative provocation test (79\% and $87 \%)$. There was also no relation between the results of the provocation test and the number and nature of symptoms. Continuous monitoring of intragastric sodium ions with a selective electrode is a practical means of assessing DGR. Results suggest that symptoms due to DGR may be related to the sensitivity of the gastric lining as well as the amounts of duodenal contents flowing back into the stomach.

(Gut 1993; 34: 1047-1050)
\end{abstract}

Reflux of duodenal content into the stomach may be an aetiological factor in the development of gastritis, gastric ulcers, and gastric neoplasia. ${ }^{1-3}$ Also bile reflux is a common endoscopic finding in patients with dyspepsia. ${ }^{4}$ Previous studies have attempted to evaluate the severity of duodenogastric reflux (DGR) and to determine whether specific constituents of duodenal juice are responsible for symptoms. The methods used have included radiological assessment ${ }^{56}$ or measurement of duodenal markers such as total or individual bile acid concentrations or pancreatic enzymes such as phospholipase A2. ${ }^{7-10}$ These assessments are often difficult to perform and involve complicated and difficult analyses.

We have investigated the sodium concentration of gastric juice as a marker of DGR, with a sodium ion selective electrode. " Depending on the rate of gastric secretion, the concentration of sodium ions in gastric juice varies between about 5 and $50 \mathrm{mmol} / \mathrm{l}$, whereas the concentration of sodium ions in bile and duodenal and pancreatic juices remain constant at about $150 \mathrm{mmol} / \mathrm{l}^{12}{ }^{13}$ Duodenogastric reflux is indicated when sodium concentrations rise above $50 \mathrm{mmol} / \mathrm{l}$. This was shown by synchronous measurement of gastric bile acid concentration and pancreatic enzyme acitivity, which are other indices of reflux into the stomach. ${ }^{11}$ Measurement of sodium concentrations is simple to perform and offers the possibility of prolonged continuous monitoring.

The aim of the present study was to assess DGR with the sodium selective electrode in normal subjects, in patients with benign gastric ulcers, and in patients with persistent pain after gastric surgery. The relation between DGR and symptoms in patients with pain after gastric surgery was also investigated by a provocation test with the patient's own bile enriched duodenal juice. ${ }^{14}$

\section{Patients and methods}

Studies were carried out on 10 healthy normal control subjects, (six men, four women, age range 28-72 years) five patients with benign gastric ulcer (three women, two men, age range 42-81 years), and 10 patients (seven men, three women, age range $44-73$ years) who had persist-

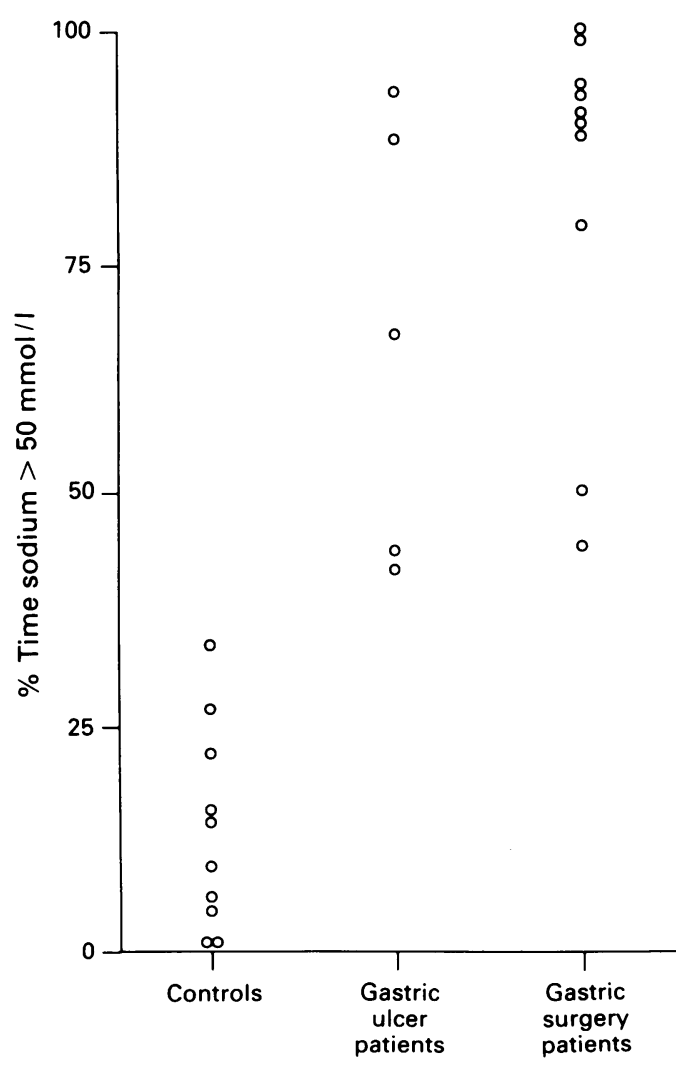

Figure 1: Duodenogastric reflux measurement by determination of sodium concentration of gastric juice. Controls $\mathrm{v}$ gastric ulcer group, $p<0.001$; controls v gastric surgery group, $p<0.0002$ (Mann Whitney U test). 

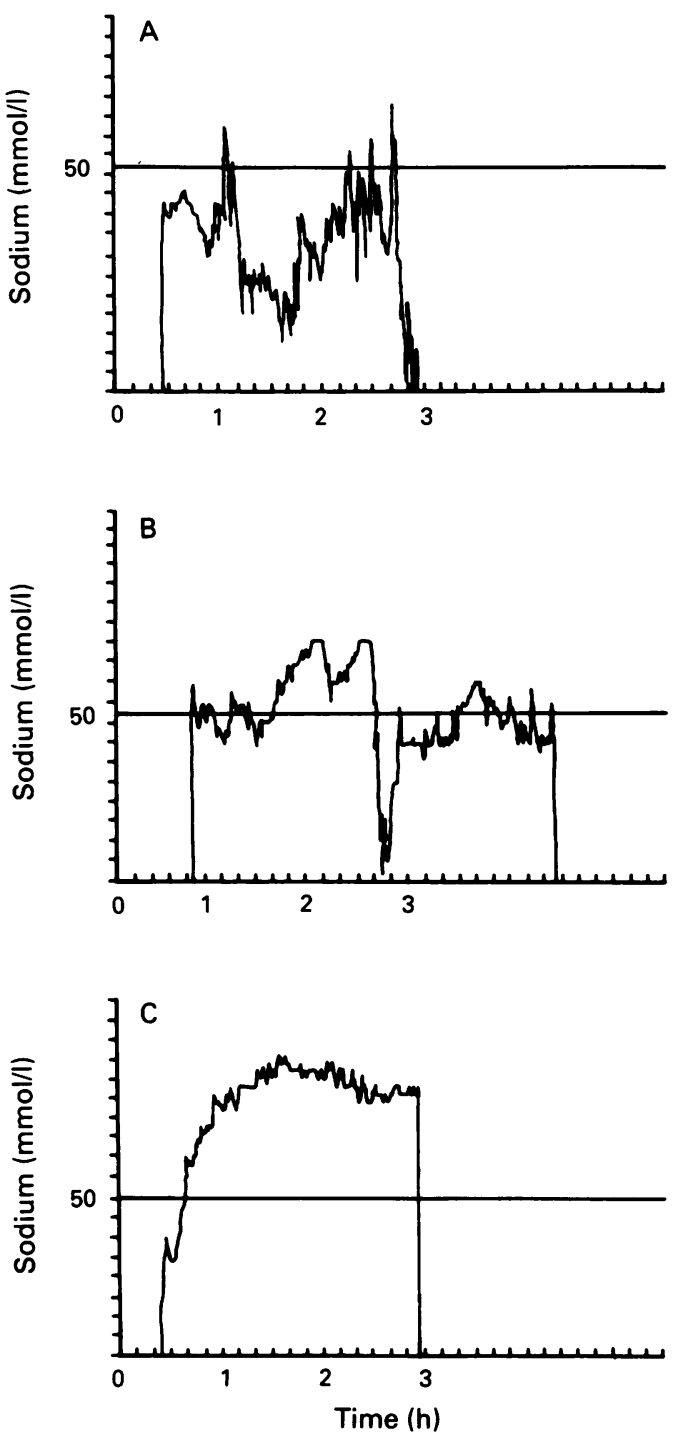

Figure 2: Fasting sodium concentration profiles of $(A) a$ control subject, $(B)$ a gastric ulcer patient, and $(C)$ a patient after gastrectomy.

ent pain (>3 months) after vagotomy and pyloroplasty, vagotomy and antrectomy, vagotomy and gastroenterostomy, or Bilroth 1 gastrectomy. This group had no evidence of ulcer on endoscopy but showed varying degrees of gastritis. Ultrasound examination was normal.

Ethics committee approval was obtained for all studies performed.

\section{MEASUREMENT OF DUODENOGASTRIC REFLUX} WITH THE SODIUM ION SELECTIVE ELECTRODE Subjects were fasted overnight and given $800 \mathrm{mg}$ of cimetidine (SKB, Welwyn, UK) orally, one hour before the test, to avoid interference with the electrical signal from hydrogen ion activity. ${ }^{11}$ After anaesthetising the subject's pharynx with $4 \%$ lignocaine spray, gastric sodium and $\mathrm{pH}$ microelectrodes (Ingold Messtechnic, Zurich, Switzerland) were introduced high into the stomach about $48 \mathrm{~cm}$ from the incisors (this precluded entry into the duodenum after operations such as gastrectomy). The electrodes were connected to a portable data logger (Synectics Medical, Stockholm, Sweden). A continuous recording of both sodium concentration $(\mathrm{mV})$ and $\mathrm{pH}$ was obtained (at intervals of two seconds) for up to three and a half hours (median value $=$ two hours 27 minutes, range from 56 minutes to 3 hours 32 minutes). Millivolt readings were converted to $\mathrm{mmol} / \mathrm{l}$ for analysis of data. Subjects were asked to note any pain during the study.

\section{BILE PROVOCATION TEST}

This was performed on the 10 patients with pain after gastric surgery who also carried out the sodium probe study. A careful history of symptoms was taken from each patient. Patients were fasted overnight and an AN20 radio-opaque tube (Anderson Products Inc, Chapel Hill, USA) was passed into the upper small intestine under fluoroscopic control. A dose of $0.05 \mu \mathrm{g} / \mathrm{kg}$ body weight of ceruletide (Farmitalia Carlo Erba Ltd, St Albans, UK) in $10 \mathrm{ml}$ saline was then given by intravenous injection over a 10 minute period. Ceruletide contains amino acid sequences that correspond to physiological hormones in humans that cause contraction of the gall bladder and bile duct and relaxation of the sphincter of Oddi. ${ }^{15}$ About $70 \mathrm{ml}$ of bile rich duodenal juice was collected by continuous low suction, and the AN20 tube was then repositioned into the stomach, about $48 \mathrm{~cm}$ from the insicors. After a 10 minute rest period $0.9 \%$ saline was infused in the stomach at a rate of $4 \mathrm{ml} /$ minute for 15 minutes with a syringe pump (model 355 , Sage Instruments). Any symptoms of discomfort were noted. The stomach was washed out with water during a 10 minute rest period and the procedure was repeated with the patient's own bile stained duodenal juice. The patient was unaware of which order the solutions were infused. A positive provocation test was documented if upper abdominal pain was present with or without nausea after introduction of duodenal contents.

\section{Results}

DUODENOGASTRIC REFLUX

Monitoring of intragastric sodium concentration was well tolerated. Duodenogastric reflux was identified when intragastric sodium concentrations exceeded $50 \mathrm{mmol} / \mathrm{l} .{ }^{.1}$ All subject groups had DGR for some of the study period; however,

TABLE I Comparison of duodenogastric reflux (DGR), additional symptoms after operation, and results of provocation tests with type of gastric surgery

\begin{tabular}{lllll}
\hline & & \multicolumn{2}{c}{$\%$ Time with DGR } & \\
\cline { 3 - 4 } & No of & Sodium & Sodium & Provocation \\
Operation & $\begin{array}{l}\text { symptoms } \\
\text { S }\end{array}$ & 50 mmolll & $>100$ mmolll & test \\
\hline B1 & 4 & 44 & 13 & + \\
B1 & 5 & 91 & 69 & + \\
B1 & 4 & 90 & 79 & + \\
B1 & 2 & 100 & 69 & - \\
V and P & 6 & 50 & 14 & - \\
V and P & 5 & 93 & 15 & - \\
V and P & 6 & 99 & 19 & - \\
V and GE & 4 & 94 & 37 & - \\
V and GE & 6 & 89 & 13 & + \\
V and A & 5 & 79 & 39 & + \\
\hline
\end{tabular}

$\mathrm{B} 1=$ Billroth 1 gastrectomy; $\mathrm{V}$ and $\mathrm{P}=$ vagotomy and pyloroplasty $\mathrm{Bl}=$ Billroth 1 gastrectomy; $\mathrm{V}$ and $\mathrm{P}=$ vagotomy and pyloroplasty;
$\mathrm{V}$ and $\mathrm{GE}=$ vagotomy and gastroenterostomy; $\mathrm{V}$ and $\mathrm{A}=$ vagotomy and antrectomy. 
TABLE II Relation between provocation test results and symptoms in patients with persistent pain after gastric surgery

\begin{tabular}{lll}
\hline & \multicolumn{2}{l}{ Provocation test } \\
\cline { 2 - 3 } Symptom & Positive (5) & Negative (5) \\
\hline Nausea & 4 & 3 \\
Vomiting & 4 & 4 \\
Heartburn & 2 & 2 \\
Acid reflux & 0 & 1 \\
Bile reflux & 4 & 4 \\
Belching & 2 & 1 \\
Fullness & 3 & 2 \\
Weakness & 3 & 3 \\
Diarrhoea & 1 & 2 \\
Weight loss & 1 & 1 \\
\hline
\end{tabular}

both groups of patients had reflux for a significantly longer proportion of study time than the normal controls (12\% of study time for normal controls, $67 \%$ for gastric ulcer patients, and $91 \%$ for gastric surgery patients; $p<0.001$ gastric ulcer $v$ controls and $\mathrm{p}<0.0002$ gastric surgery $v$ controls; Fig 1). Figure 2 shows typical sodium profiles from subjects in each of the three groups. The normal subject displayed only short bursts of reflux with a maximum duration of four minutes. The patient with a gastric ulcer had intermittent episodes lasting up to an hour, whereas continuous reflux occurred in the patient after gastrectomy.

RELATION BETWEEN PAIN AND DGR AFTER GASTRIC SURGERY

Patients with persistent pain after gastric surgery often had several symptoms (Tables I and II). Nine out of 10 patients had three or more symptoms as well as pain; the main additional problems were nausea, vomiting, bile reflux, and weakness. (Bile reflux was usually identified by a particular taste in the patients mouth, which was recognised from previous bile vomiting.) There was no association between the number of symptoms and the severity of DGR as determined by the sodium electrode (Table I). Neither was any particular symptom present in patients with a positive bile provocation test that was not present in those patients with a negative result (Table II).

There was no correlation between the results of provocation testing and the severity of DGR as determined by the sodium electrode. Five out of 10 patients had a positive result on provocation with their duodenal aspirate, developing epigastric pain. The mean duration of DGR (sodium $>50 \mathrm{mmol} / \mathrm{l}$ ) was $79 \%$ of study time for patients with a positive result and $87 \%$ for patients with a negative result. There was no relation between the results of provocation testing and the number or nature of symptoms (Table II).

All three patients after vagotomy and pyloroplasty had negative provocation tests and average gastric sodium concentrations were above 100 $\mathrm{mmol} / \mathrm{l}$ for only $16 \%$ of the study. Conversely, three our of four patients after Billroth 1 gastrectomy had positive provocation tests and sodium concentrations above $100 \mathrm{mmol} / \mathrm{l}$ for an average of $57 \%$ of the study time.

Discussion

Clarification of the role of DGR in gastric pathology is limited by the techniques available for its measurement. This study shows that continuous monitoring of the sodium concentration in gastric juice with a sodium ion selective electrode is a practical means of assessing fasting DGR, as it is well tolerated and suitable for ambulant use.

The important findings are that although transient DGR is present in healthy subjects, it occurred for a significantly greater proportion of the study time in patients with gastric ulcers and in patients with persistent pain after gastric surgery (Fig 1).

There has been conflicting evidence concerning the occurrence of DGR in both normal controls and in association with gastric ulcers. ${ }^{36}{ }^{10} \mathrm{In}$ our study continuous monitoring showed that DGR occurred in all patients with gastric ulcers, and that it occurred for a significantly greater proportion of the study time than in normal controls. This is consistent with the suggestion that DGR is involved in the aetiology of gastric ulcers.

Persistant pain is often reported after gastric surgery and management is difficult. These patients have been reported to have greater amounts of duodenogastric reflux than controls ${ }^{814}$ and some surgeons have relied solely on evidence of DGR to select patients for remedial surgery. ${ }^{16}$ Others have used provocation testing to identify those patients in whom DGR is actually responsible for symptoms. We have combined these approaches by examining both the degree and duration of DGR and the response to provocation testing in the same subjects. The results indicated that although all patients with persistent pain after gastric surgery had DGR, there was no correlation between symptoms and the severity of DGR (Table I). There was also no correlation between severity of DGR and results of provocation testing.

It was interesting that all three patients after vagotomy and pyloroplasty had negative provocation tests and only short periods in which DGR fluid contained high concentrations of sodium (Table I) compared with three out of four patients after Billroth 1 gastrectomy who had positive provocation tests and high sodium concentrations. More studies are needed to investigate this finding.

Symptomatic patients with excessive DGR and a positive provocation test might be expected to benefit from treatment designed either to prevent DGR or to protect the gastric mucosa. Conversely, a negative provocation test suggests that the patient's pain is not due to the presence of irritant duodenal juice in the stomach, but could be associated with abnormal motility associated with DGR, ${ }^{18}$ or might be due to an unrelated cause. Trials with cytoprotective agents or prokinetic drugs - for example, cisapride - may clarify these issues.

This study highlights the fact that the mere presence of noxious agents in contact with the gastric mucosa does not prove that they cause symptoms. Symptoms may be due to greater gastric mucosal sensitivity rather than to the presence of increased concentrations of such agents. Continuous monitoring with the sodium selective electrode has widened our understand- 
ing of DGR and its clinical consequences in individual patients.

1 Meshkinpour H, Marks JW, Schoenfield LJ, Bonnoris GG Carter S. Reflux gastritis syndrome: mechanisms of symptoms. Gastroenterology 1980; 79: 1283-7.

2 Houghton PW, Mortensen NJMcC, Thomas WE, Copper MJ, Morgan P, Burton P. Intragastric bile acids and histological changes in gastric mucosa. Br $\mathcal{F}$ Surg 1986; 73: 354-6.

3 Frizis HI, Whitfield PF, Hobsley M. Maximal gastric secretion and duodenogastric reflux in patients with gastric
or duodenal ulcer and in control subjects. Brf Surg 1987; 74: or duodeng

4 Eyre-Brook IA, Holroyd AM, Johnson AG. Is bile reflux at endoscopy a significant finding? Scand $\mathcal{F}$ Gastroenterol 1984 19 (suppl 92): 203-5.

5 Capper WM, Airth GR, Kilby JO. A test for pyloric regurgitation. Lancet 1966; ii: 621-3.

6 Muller-Lissner SA, Fimmel CJ, Sonnenburg A, Will N, Muller-Duysing W, Heinzel F, Blum AL. A novel approach to quantify DGR in healthy volunteers and in patients with type 1 gastric ulcer. Gut 1983; 24: 510-8.

7 Dewar P, King R, Johnson D. Bile acid and lysolecithin concentrations in the stomach of patients with gastric ulcer before operation and after treatment by highly selective before operaling and af vagotomy, Billroth 1 partial gastrectomy as

8 Gadacz TR, Zuidema GD. Bile acid composition in patients with and without symptoms of postoperative reflux gastritis. Am $\mathcal{F}$ Surg 1978; 135: 48-51.

9 Smythe A, Eyre-Brook IA, Mangnall D, Johnson AG.
Patterns of individual bile acid reflux in gastric ulcer disease and after cholecystectomy. Surgical Research Communications 1991; 10: 139-45.

10 Eyre-Brook IA, Smythe A, Bird NC, Mangnall Y, Johnson AG. Relative contribution of bile and pancreatic juice duodenogastric reflux in gastric ulcer disease and cholelithiasis. Br $\mathcal{F}$ Surg 1987; 74: 721-5.

11 Smythe A, Bird N, Johnson AG. Continuous monitoring of sodium ion concentration in the human stomach - a new technique for the detection of duodenogastric reflux. Digestion 1992; 52: 20-5.

12 Fiddian-Green RG, Russell RC, Hobsley M. Secretin induced pyloric reflux: verification of the mathematical formula for eliminating reflux in gastric aspirate. Br $\mathcal{F}$ Surg 1972; 59: 903.

13 Hobsley M. Tests of gastric secretory function. In: Sircus W Smith AN, eds. Scientific foundations in gastroenterology.

14 Meshkinpour H, Marks JW, Schoenfield LJ, Bonnoris GG Carter S. Reflux gastritis syndrome: mechanism of symptoms. Gastroenterology 1980; 79: 1283-7.

15 Bertaccini G, Braibanti T, Uva F. Cholecystokinetic activity of the new peptide caerulein in man. Gastroenterology 1969;56: 862-7.

16 Hoare AM, McLeish A, Thomson H, Alexander-Williams J. Selection of patients for bile diversion surgery: use of bile acid measurements in fasting gastric aspirate. Gut 1978; 19 . 163-5.

17 Keane FB, Dimagno EP, Malagelada J-R. Duodenogastric reflux in humans: its relationship to fasting antroduodenal motility and gastric, pancreatic, and duodenal secretion. motility and gastric, pancreatic,

18 Johnson AG. The effects of cisapride on antroduodenal coordination and gastric emptying. Scand $\mathcal{F}$ Gastroenterol 1989; 24 (suppl 165): $36-43$. 